\title{
Imperatives for Establishing Corporate Ethics: Examining National Strategic Planning and Public Policy
}

\author{
Sesan Ayodele \\ Achievers University \\ Owo, Nigeria \\ Uyi Lawani* \\ Marshall University \\ Division of Management \\ Lewis College of Business \\ Corbly Hall 413 \\ One John Marshall Drive \\ Huntington, WV 25755, USA \\ Sylvester L. Itanrin \\ Adekunle Ajasin University \\ Department of Philosophy \\ Akungba-Akoko, Nigeria
}

\begin{abstract}
Successive governments in Nigeria (colonial, military, civilian) have made deliberate efforts to evolve a nation-state governance with corporate ethics. They have considered this useful for the facilitation of the pace of socio-economic development. Despite the robustness of the country's resource endowments, development policies and policy instruments as documented in previous and current development plans, growth has been historically hampered and stymied. The country's rulers and the central government have therefore been evaluated by the generality of the populace in terms of how much each unit/component gains without the reciprocal consideration of how much each has put into it. Bearing in mind the heterogeneity of the nation, and the rivalry among the federating units, Nigeria remains underdeveloped with stagflation pressures and poverty. To alleviate this situation, this paper proposes an infusion of corporate ethics into all sectors of the polity led by small and medium scale enterprises.
\end{abstract}

Keywords: governance, corporate ethics, strategy, economy

\section{Introduction}

One main concern for effective transformation of the country to a more desired development status, particularly under the ongoing policy reform measures, relates to the need to evolve an appropriate development framework within an established corporate ethics regime. Such a system (connected to production, allocation and the country's utilization culture and tradition) will be particularly useful for the attainment of specific objectives like the Millennium Development Goals (MDGs). In order to evolve such a framework, this paper proposes to make a broad review of the socio-economic management processes in the Nigerian economy. The paper seeks to establish a base for the imperatives of the evolution of corporate ethics to move the economy forward desirably. Accordingly, the paper is organized into five parts. This introduction is followed by a discussion of Socioeconomic Management in Nigeria, Background Information. The third part highlights the existing Socioeconomic Development status of the country. Part four touches on the Way Forward while part five concludes the paper and mentions some cogent policy issues.

\section{Socio-economic Management in Nigeria: Background information}

Nigeria is vastly endowed with a lot of primary resources (human and material) in most cases in excess of its domestic requirements. Against the background of the magnitude of the deposit of these resources, the National Planning Commission (NPC) in the National Economic Empowerment and Development Strategy (NEEDS) document comments that: "Nigeria has the potential to become Africa's largest economy and also an important player in the global economy if the resources are effectively managed" (NPC 2004). Incidentally, a sizeable proportion of the resources remain untapped, e.g., bitumen, nuclear, solar, geothermal, etc. The resources from the few ones tapped have 
been grossly mismanaged (Federal Government of Nigeria, FGN, 1986). It is therefore suspected that if this mismanagement continues unbated, it would be difficult to attain the MDGs and the goals of economic development, particularly, in the absence of established corporate ethics. Perhaps, given the foregoing, the World bank/IMF endorsed the Structural Adjustment Program (SAP) of economic policy reforms adopted in 1986 (FGN 1986). Specifically, SAP aimed at the removal of the perceived distortions arising from resource mismanagement which for long had prevented the economy from attaining sustained, self-reliant, widely beneficial economic growth and development. Consequent upon SAP's failure to attain this goal, the Vision 2010

Report was adopted to reinforce SAP's policy strength as another reform policy package (FGN 1998). Despite the laudability of these policy packages, the country was left with more complex economic problems broadly summarized as follows:

- Huge external and internal indebtedness.

- Chronic fiscal deficit; and

- Serious economic decline.

These problems reflected in stagflation pressures and worsening poverty level amidst abundant primary resources. Thus, in its recognition of these complex problems, the Obasanjo-led civilian administration introduced the Nigerian Economic Policy (NEP), 1999-2003, focusing on a "market orientation, private sector-led development approach, highly competitive environment, technology driven, broad-based, humane and open" policy (FGN 1999). Towards the attainment of these ends, policy instruments commissioned included:

1. Stabilized market-responsive exchange rate (within narrow bands and with sufficient predictability);

2. Reduced interest rate (to reach single digit within the shortest possible time);

3. Reduced total tax burden to a minimum of $30 \%$ for corporate and personal incomes;

4. Low customs tariff, especially for production inputs (at less than $10 \%$ with in-built incentives for local producers);

5. Shift in government expenditure structure in favour of productive socio-economic sector;

6. Ensuring the availability of steady and adequate fuel supply;

7. Enhancement of workers income, particularly in the public sector;

8. Rehabilitation and reconstruction of infrastructure such as electricity, roads and water supply,

9. High priority to agriculture, manufacturing, medium enterprise and the informal sector;

10. Institutional rationalization of government and the intensification of the privatization program and;

11. The operation of cooperative federalism to ensure the inter-tier policy consistency and effectiveness among the federating units (FGN 1999).

Given these policy instruments, growth rate targets were set for attainment within the 1999/2003 period for some macroeconomic variables as shown in Table 1 below. Against the background of these established targets, the civilian administration continuously pursued a regime of macroeconomic and sectoral policies which include:

- Monetary policies focused on price and exchange rate stability.

- A low interest rate regime to support the real sector of the economy.

- Ensuring the achievement of a moderate inflation in the medium term.

- The stabilization of exchange rate via the sustenance of Inter-bank Foreign Exchange Market (IFEM).

- The rehabilitation of some infrastructural facilities.

- Increase in the level of government revenue for the promotion of overall economic development and subsequent reduction of poverty.

Table 1: Macroeconomic variable Target in Percentage (1999/2003)

\begin{tabular}{|c|l|c|c|c|}
\hline S/N & Macroeconomic Variables & 1999 Status & 2003 Target & 2003 Actual Level \\
\hline 1 & Real GDP Growth Rate & $2.4 \%$ & $10 \%$ & $10.24 \%$ \\
\hline 2 & Inflation Rate & $13 \%$ & Single Digit & $14 \%$ \\
\hline 3 & Capacity Utilization & $35.89 \%$ & $70 \%$ & $46.2 \%$ \\
\hline 4 & Population Literacy Level & $80 \%$ & $57 \%$ & $57 \%$ \\
\hline 5 & Infant Mortality per 1000 & 78 & 50 & 75.1 \\
\hline 6 & Maternal Mortality per 100,000 & 800 & 400 & 1000 \\
\hline
\end{tabular}


The inspiration for these policies was couched under some desirable guiding principles which marked the civilian administration differently from the military government in significant ways. Though lacking in corporate ethics, these guiding principles (FGN 1999) were that:

- The Nigerian economy always belongs to the people; the general well-being of the people should be the over-riding objective of government and the proper measure of performance.

- Economic management should involve total commitment of leadership at all tiers of government and the populace must be mobilized without creating a bloated government;

- Government would be lean, efficient, honest, transparent, cooperative and friendly; and operate based on extensive devolution of power. Government will function mainly as a facilitator;

- The primary role of government would be to ensure, in cooperation with the private sector, the urgent creation of adequate and efficient infrastructure particularly, energy, telecommunications, water and financial services. Government will create a positive and internationally competitive environment for economic activities.

- Private enterprise, private effort and non-governmental action should play the major role in achieving the goals of the society and the derived targets of government.

- Everything should be done to foster a strong work ethic toward driving productivity.

It is interesting to note that the need to evolve a strong work ethic was recognized by the administration. Nonetheless, it was not incorporated into its policies. Pertinent to reiterate that the foregoing economic development targets, policies and policy instruments and the associated guiding principles of the civilian government were couched under the need "to revive and grow Nigeria's comatose economy, significantly raise the standard of living of the people and subsequently put Nigerians back to gainful work and create new employment opportunities to reposition the Nigerian economy to participate beneficially in the globalizing world" (FGN 1999). To consolidate the achievement of the foregoing program and policy instruments, particularly those of the NEP, 1999-2003 (Table 1), the National Economic Empowerment and Development Strategy (NEEDS) was prepared and launched in 2004. The conceptual issues in NEEDS were built around four goals: Poverty Reduction; Wealth Creation; Empowerment Generation; and Value Reorientation (National Planning Commission, NPC, 2004). The framework for the actualization of these goals was based on three pillars:

- Empowering people and improving social delivery;

- Fostering Private Sector-led growth through the creation of appropriate enabling environment and;

- Enhancing the efficiency and effectiveness of government by changing the way government does its work (NPC 2004).

Admittedly, the implementation of the NEEDS policy reform program seems to have recorded some statistical achievements. For example, official records show that tremendous progress has been made in poverty reduction from $70 \%$ in 2003 to 56\% in 2005; GDP growth rose from 3.3\% in 1999 to 6\% within the 2004/2007 period; external reserve rose from $\$ 4$ billion in 1999 to $\$ 43$ billion while external debt of about $\$ 34$ billion in 2003 has almost disappeared by 2007. Additionally, the inflation rate appears to have declined to an average of single digit. In practical terms, most of these statistical achievements are contestable. There are still some outstanding issues and challenges that must be addressed to effectively put economic development on its proper course. Apart from the issues of poverty, unemployment, infrastructure etc., other challenges relate to the need to meet the aspirations of the MDGs by 2015. It is important to recognize that there remains one missing link that has been continuously neglected in all the past policy documents/plans. This policy related negligence has created a serious loophole in the implementation, and thus, the success of the government's programs. It is the establishment of a framework for corporate ethics in policy/plan documents. Corporate ethics is herewith perceived as the appropriate socio-economic culture and tradition of doing things in the most appropriate way. It embraces the culture of optimal production, equitable allocation, effective utilization, maintenance, monitoring and evaluation. It has become necessary therefore to examine the existing status of the Nigerian economy, its alignment with corporate ethics, and to visualize the way forward.

\section{The Existing Status of the Nigerian Economy}

Theoretically and empirically, the structural and sectoral contributions of the primary, secondary and tertiary sectors of an economy determine a country's development status and its position on the global development spectrum. The magnitudes and trends of socio-economic development also indicate a country's economic growth trend. The primary sector (agriculture and mining) is engaged in the extraction of renewable and non-renewable natural resources. The secondary sector (manufacturing, utilities and construction activities) is engaged in the production of goods relying on inputs from the primary sector and also from itself. The tertiary sector (all the services activities such as transport, communication, distributive trade, finance and insurance, housing, community, social and personal services) takes care of the distribution of goods and services produced in the two sectors. 
At the initial stage of economic development, the contributions of the primary sector to output, income and employment appear to be predominant. As the economy grows and develops, the contributions of the primary sector steadily decline, yielding place to those of the secondary sector. At this level, the productive sectors of the economy help to provide appropriate solutions to the pressing problems of economic development, particularly under proper corporate ethics and good governance. At the advanced stage of development, the contribution of the tertiary sector expands and possibly exceeds those of the other sectors. Development problems that arise at this level are theoretically taken as temporary and marginal. Regardless of the level of economic development in the country, each of the three sectors should be growing in absolute terms, although at different rates. Nonetheless, a situation in which any one of the sectors declines in absolute terms would be taken as inimical to smooth and orderly development of the economy, particularly in the absence of corporate ethics. Against the background of the foregoing theoretical exposition, Table 2 represents some data on Nigeria's structure of output, income and employment proxied by the nation's GDP. The table captures statistical information that includes a diversification index; the trends and magnitudes of some socio-economic development indicators. The table helps to visualize Nigeria's current economic development status and helps to identify weak areas that may require prompt policy attention.

Table 2: Economic Development Status of Nigeria 1995-2005

\begin{tabular}{|c|c|c|c|c|c|c|c|c|c|}
\hline & & 1995 & 1999 & 2000 & 2001 & 2002 & 2003 & 2004 & 2005 \\
\hline \multirow{3}{*}{$\begin{array}{l}\text { Primary } \\
\text { Sector }\end{array}$} & Agric & 38.76 & 40.64 & 40.15 & 42.30 & 42.14 & 41.01 & 40.98 & 41.21 \\
\hline & Mining & 12.93 & 11.46 & 11.46 & 10.32 & 9.00 & 10.37 & 11.14 & 11.13 \\
\hline & Total & 51.69 & 52.10 & 52.10 & 52.62 & 51.14 & 51.38 & 52.14 & 52.34 \\
\hline \multicolumn{2}{|c|}{ Secondary Sector } & 9.23 & 8.50 & 8.50 & 8.72 & 9.58 & 7.0 & 8.12 & 8.22 \\
\hline \multicolumn{2}{|c|}{ Tertiary Sector } & 39.08 & 39.40 & 39.40 & 38.66 & 39.28 & 41.62 & 39.76 & 39.44 \\
\hline \multicolumn{2}{|c|}{$\begin{array}{l}\text { Diversification } \\
\text { Index }\end{array}$} & 1.34 & 1.36 & 1.36 & 1.35 & 1.36 & 1.36 & 1.36 & 1.36 \\
\hline \multicolumn{2}{|c|}{ Oil Revenue $(\mathrm{N})$} & 78.1 & 76.3 & 83.5 & 83.5 & 76.5 & 76.8 & & 75 \\
\hline \multicolumn{2}{|c|}{$\begin{array}{l}\text { Oil Revenue } \\
\text { (N'bn) }\end{array}$} & 21.9 & 23.7 & 16.5 & 16.5 & 23.5 & 23.2 & & 25 \\
\hline \multicolumn{2}{|c|}{$\begin{array}{c}\text { Capital Utilization } \\
(\%)\end{array}$} & 36.5 & 35.9 & 36.1 & 39.6 & 44.3 & 46.2 & & 39.1 \\
\hline \multicolumn{2}{|c|}{$\begin{array}{l}\text { External Debts } \\
(\$ b n)\end{array}$} & 27.1 & 28.1 & 28.3 & 28.4 & 28.4 & 28.4 & 35.9 & 20.5 \\
\hline \multicolumn{2}{|c|}{ Inflation } & 29.3 & 13.0 & 6.9 & 18.9 & 12.9 & 14.5 & 15.0 & 17.9 \\
\hline \multicolumn{2}{|c|}{ Exchange N/\$ } & 81.2 & 92.3 & 101.7 & 111.94 & 120.97 & 129.36 & 133.50 & 131.66 \\
\hline \multicolumn{2}{|c|}{ Saving Rate } & 10.1 & 5.3 & 4.9 & 5.0 & 3.7 & 3.2 & & \\
\hline \multicolumn{2}{|c|}{ Lending Rate } & 20.8 & 27.2 & 26.4 & 31.2 & 25.7 & 21.6 & & \\
\hline \multicolumn{2}{|c|}{ Spread \% } & 10.7 & 21.9 & 21.5 & 26.2 & 22.0 & 22.0 & 18.4 & \\
\hline \multicolumn{2}{|c|}{$\begin{array}{l}\text { Budgetary Balance } \\
\text { (N'bn) }\end{array}$} & & 15.9 & -90.4 & -221.0 & -301.2 & -202.8 & -172.6 & 36.6 \\
\hline \multicolumn{2}{|c|}{ Reserves ( $\$$ 'bn) } & & & 9.4 & 10.4 & 7.7 & 7.5 & 17.0 & 28.3 \\
\hline \multicolumn{2}{|c|}{ GDP (N'bn) } & & & & 431.8 & 451.8 & 495.0 & 527.6 & 560.4 \\
\hline \multicolumn{2}{|c|}{ Growth Rate (\%) } & & & 5.6 & 3.3 & 1.4 & 10.9 & 6.1 & 6.9 \\
\hline
\end{tabular}

Source: CBN Statement of Accounts and Annual Reports (several series)

The table shows the dominance of the primary and tertiary sectors (of the Nigerian economy) in their contributions to output, income and employment. The contributions tend to follow increasing trends averaging $52.35 \%$ and $39.02 \%$ for the primary and tertiary sectors respectively. The contribution from the secondary sector distantly lagged with an average contribution of $8.64 \%$ within the period shown in the table. The economic indications of this pattern of economic structure even with the prevailing economic reform policies, policy instruments and the Obasanjo-led civilian administrative guiding principles are that the Nigerian economy:

1. Did not move beyond the initial stage of economic development after five decades into post-independence era;

2. Is more of a trading economy involved in the distribution of foreign goods. The secondary sector of the economy has been almost non-existent; there has been little transformation of goods from primary to secondary;

3. Had not really diversified its productive base - diversification index averaged about 1:35; 
4. Had inordinately low contributions from the secondary sector $(8.64 \%)$ which is incapable of raising the country's desirable rate of economic development.

These indications therefore explain why Nigeria is currently regarded as a Third World Country (TWC), languishing at the initial stage of economic development. The nation has remained largely monocultural five decades after its independence. In addition, the absence of an established and coherent body of corporate ethics in the production, allocation and utilization systems occasioned some serious and pressing economic development problems. These include capacity under-utilization (less than 50\%), rates of inflation (17.9\%) and unemployment rate (above 5\%), external debt overhang ( $\$ 20.5$ billion), deficit budget (N172.6 billion in 2004) etc., as shown in the table.

A comparative analysis of the above development indicators in Nigeria and some other countries where corporate ethics exist is presented below.

The countries are South Africa, Korea, Japan and the USA.

Table 3: Development Indicators in Nigeria and some selected Countries (2002)

\begin{tabular}{|l|c|c|c|c|c|}
\hline Indicators & Nigeria & South Africa & Korea & Japan & USA \\
\hline GDP per capita (\$) & 411 & 2,980 & 7,660 & 31,740 & 24,740 \\
\hline Energy Consumption per capita & 141 & 2,399 & 2,863 & 3,642 & 7,918 \\
\hline Gross Enrolment Rates (Pry.) & 76 & & 102 & 102 & 104 \\
\hline (i) Male & 85 & & 101 & 102 & 104 \\
\hline (ii) Female & 67 & & 103 & 102 & 104 \\
\hline Infant Mortality (1,000) & 191 & 69 & 12 & 6 & 10 \\
\hline Measles Immunization & 34 & 63 & 93 & 66 & 98 \\
\hline DPT & 29 & 67 & 74 & 87 & 97 \\
\hline Malnutrition: Child under 5(\%) & 43 & & & 2.5 & \\
\hline Life Expectancy & 51 & 63 & 71 & 79 & 76 \\
\hline Female Advantage (\%) & 3.2 & 6 & 7.5 & 6.1 & 6.8 \\
\hline
\end{tabular}

Source: Ajakaiye (1997).

It is apparent from this table that Nigeria's GDP per capita was about $\$ 411$ in 2002 . This was about $57 \%$ of the per capita income of the rest of Sub-Saharan Africa, 13.8\% of South Africa's, 5.4\% of Korea's, 1.3\% of Japan's and 1.7\% of the U.S.' Besides, there are indications that income in Nigeria is highly skewed in favour of rich households where the top 20\% of the household is estimated to receive about $49 \%$ of the income (Ayodele, 2003). The bottom 20\% keep only 5\% of the income (Ayodele, 2003). With the information presented in Table 3, it is certain that the major characteristics of the Nigerian economic development experience is relatively poorer than those of other selected countries. The overall explanations for these characteristics as contained in Tables 2 and 3 relate to;

1. The heavy reliance on one sector of the economy (crude oil) - $76.8 \%$ of total revenue; $82.8 \%$ of foreign trade; $90 \%$ of foreign exchange; and above $78 \%$ of national energy consumption;

2. Weak industrial base accounting for about $8 \%$ of output, income and employment proxied by the GDP.

3. Increasing external and internal debt overhang averaging $\$ 30$ billion and N1,017 billion respectively until the time of debt relief;

4. Inadequacy of infrastructural facilities and low quality of social services;

5. Unhelpful stagflation pressures partially due to inefficient utilities despite the privatization-cum-commercialization of hitherto government owned and operated institutions.

As mentioned earlier, the Nigerian economy is lopsidedly anchored on the primary and tertiary sectors. A situation that is certainly undesirable. The Vision 2010 document, reinforced by recent government policy pronouncements and policies, particularly NEP (1999-2003) and NEEDS (2004). The desired state is to promote the secondary sector to replace the primary sector in its domineering contributions to the GDP via a private sector-led growth. The hope is that this will lead to benefits for the country's economy given the extant globalization paradigm, especially if fueled by good governance. Against this background, the primary aspiration for Nigeria should be to apply corporate ethics in production, allocation and utilization in order to: "alter the structure of production and consumption activities so as to diversify the economic base, reduce dependence on crude oil and imports, create wealth and jobs and put the economy on a path of self-sustaining and non-inflationary growth, thereby reducing poverty" (NISER, 2001). 


\section{Priority Areas for Immediate Government Intervention}

It is important to note that, for about the first time in the history of the socio-economic and political management of the Nigerian economy, the Obasanjo-led civilian administration deliberated on the attributes of good governance required to advance the best interest of the economy. We mentioned this earlier regarding what the administration called its guiding principles. Some of such guiding principles culminated in what the World Bank (1997) identified as the indicators of good governance to move the economy forward and they embraced the administration's stance (FGN 1999). These attributes, listed below, border on corporate ethics but without any mechanism for monitoring and evaluation.

1. Accountability of government officials including politicians and civil servants;

2. Transparency in government procedures;

3. Predictability in government behaviour and the expectation of rational decisions;

4. Openness in government transactions;

5. The rule of law and an independent judiciary;

6. Free flow of information and vigorous protection of the freedom of the press; and

7. Respect for human rights and mass participation.

Against the background of these guiding principles which the Jonathan-led government were expected to uphold for the effectiveness of its policies, it was plausible to assume that:

1. Under a fully democratized system, Nigeria constitutes a society where the rule of law. due process, freedom and justice would reign supreme. The principles and practice of federalism would be perfectly put on course under a corruption free society;

2. The increasing productivity of industrialized economies would not allow for short run declines in the demand for crude oil which is crucial to Nigeria's economy;

3. At this stage of national consciousness, Nigerians are creators and beneficiaries of economic development, implying that under prudent management, they constitute an asset for rapid economic development. Consequently, operators in the private and informal sectors of the economy are willing to be mobilized for effective economic transformation (Ajakaiye \& Ayodele, 2001).

In order to adequately aspire within the framework of the above assumptions and desirable guiding principles for good governance and economic transformation, it is pertinent for the political class to understand the structural fundamentals about the economy and society. In this regard, all members of the political class aspiring to manage the Nigerian economy must be educated and informed about the structure of these fundamentals. Applying corporate ethics, political will and the readiness to provide a sense of direction, the political class may be able to alter the weak structure of the economy. In the light of high levels of corruption, indiscipline and unaccountability, institutions (private, public, legislature, Executive branch, NGOs, etc.) must be willing to accept changes for good governance. These institutions should readily accept and embrace sincere reform packages that include the establishment of corporate ethics. It is pertinent to note that the government's resources are meager at best and misappropriated at worst, and as such may be inadequate to fund the reforms anticipated. It will therefore be necessary to consider alternative means by which the private and informal sectors of the economy could mobilize to initiate and establish corporate ethics in governance. The important issue of how to get these groups coordinated and mobilized as the engine for reform becomes crucial. Put differently, what can these sectors do and how should they do it to make a success of the reform programs that will boost the secondary sector of the economy? Below, we proffer suggestions in the discussion of our conclusion to this paper

\section{Conclusion}

Given the major development indicators examined and discussed in this paper, Nigeria's policy priority attention should focus on the establishment of corporate ethics to enable a restructuring of the economy toward diversification. A regime that will usher in good governance, wealth creation and increased employment. The three interrelated economic priorities of private sector driven industrialization, infrastructural development and budgetary reform should be of major concern to the government. From the government end, the Ministries of Commerce and Industries and Finance; the Economic Planning Commission; the Central Bank of Nigeria (CBN); the Bureau for Public Enterprise (BPE); the Utilities Charges Commission (UCC) will take the lead in establishing corporate ethics and acting on these priorities. From the infrastructure development related and public utilities angle, institutions like the Power Holding Company of Nigeria (PHCN), Nigerian Telecommunications (NITEL), Nigerian National Petroleum Corporation (NNPC), the Nigerian Railway Corporation (NRC) and the Ministry of Works should be involved and engaged. From the private sector/business end, small and medium scale enterprises (SMEs) should be engaged. 
They are the major drivers of the nation's economy and must be crucial to altering the structure of the economy in favor of the secondary sector. The experience of other developing nations has proved that SMEs contribute a much higher proportion to the output, income and employment of such nations. SMEs should take the forefront in establishing governance related corporate ethics.

\section{References}

Ajakaiye, O. (1997). Plausible Economic Scenarios for Nigeria's Vision 2010. Economic Development Department, NISER, Ibadan.

Ajakaiye, O. (2000). Economic Development in Nigeria: A review of Experience Bullion. Publication of the CBN, 26: 1.

Ajakaiye, O. \& Akinbinu, B. (2002). Strategic Issues in Nigerian Development in a Globalising and Liberalising World; NISER, Ibadan.

Ajakaiye, O. \& Ayodele, A. (2001). Nigeria's Investment Profile: Which Way to Deliver? NESG, Economic Indicators, 7: 3 .

Ajakaiye, O. \& Ayodele, A. (2001). Nigeria at Sixty: what the Future Holds for Nigeria. Commissioned paper by Bashorun Randle, KPMG House, Ilupeju, Lagos.

Ayodele, A. \& Falokun, G. O. (2003). The Nigerian Economy: Structure and Pattern of Development. JODAD Publishers, Oyo Road, Ibadan.

Babalola, Y.A. (2012). The Prospects and Challenges of Accounting Education: A Case Study of Nigeria Tertiary Institutions. The review of Financial and Accounting Studies. Eurojournals Publishing Inc. http://www.eurojournals.com/REFAS.htm

Central Bank of Nigeria (2005). Microfinance Policy, Regulatory and Supervisory Framework for Nigeria, December 2005.

Dancy, J. (2004) Ethics without Principles. Oxford: Oxford University Press.

Federal Government of Nigeria (1986). Structural Adjustment Program for Nigeria (Federal Ministry of Information), Lagos.

Federal Government of Nigeria (1999). The Nigerian Economic Policy, 1999 - 2003. 17

Greenwood, M. S. (1957). The rise of Professionalism: A Sociological Analysis. Berkeley: University of California Press.

National Planning Commission (2004). National Economic Empowerment and Development Strategy. Abuja, Nigeria. Nigerian Institute of Social and Economic Research (2001): NISER Review of Nigerian

Development, 2000 (The State in Nigerian Development, 1990-91); NISER, Ibadan

Oyelaran-Oyeyinka, B. (2007). SME: Issues Challenges and Prospects. A paper presented at the Financial System Strategy 2020, International Conference organized by the Central Bank of Nigeria at Transcorp Hilton Hotel, Abuja, 18th -20th June 2007.

Phillips, A. O. \& Ajakaiye, D. O. (1993). The Nigerian Economy and Society: EconomiclPolicy and Development, 1990-91. NISER, Ibadan.

Rawlings, M. \& Rawlings P. (2000). Unprincipled Ethics, Moral Particularism. Brad Hooker and Margaret Olivia Little (eds.). Oxford University Press.

World Bank (1997). Global Development Finance: A World Bank Book (Washington).

Toulmin, S. C. (1950). The Place of Reason in Ethics. Cambridge: Cambridge University Press.

UNESCO-EFA (2009). Global Monitoring Report. Paris: UNESCO. 